\title{
Challenges in Environmental Impact Assessment (EIA) In Land-scarce Singapore
}

\author{
Charles CC Lee ${ }^{1}$, Rios Anita ${ }^{1}$ \\ ${ }^{1}$ Newcastle Australia Institute of Higher Education \\ 8 Temasek Blvd, Suntec Tower 4, Singapore 038986 \\ charles.cc.lee@newcastle.edu.au
}

\section{Extended Abstract}

For a modern and advanced economy - Singapore - the development of major infrastructure projects, such as mass rapid transit stations, seaports, major housing development estates, and manufacturing plants, are Not governed by environmental impact assessment (EIA) regulations. This is in stark contrast to a well-developed set of EIA laws operating in all her 9 ASEAN neighbours. However, ad hoc EIAs are conducted on a "voluntary basis" by governmental agencies (e.g. Public Utilities Board, National Environmental Agency) for some major projects. Such EIA projects are contracted to consulting companies who perform the scope-of-work under specific guidelines spelled out by the government. One major drawback is that this scope does not have a significant public participation component and a thorough mitigation plan.

The public review of the EIA reports is by invitation, restricted and tedious. Only in 2019, the Land Transport Authority

(LTA) openly released the draft EIA reports via the Internet on the cross-island mass rapid transit line for public view [1] although LTA claimed there had been extensive consultations prior and that feedback and mitigating measures were considered in the published EIA reports.

Recently, there has been increasing debate on the need to clear precious forests for housing development based on limited biodiversity studies [2]. Additionally, there is a call for legislating EIA by academics [3] and nature groups [4] in order to provide a thorough evaluation of possible environmental impacts and mitigation measures before major projects or projects in environmentally sensitive areas are allowed to commence activities with irreversible impacts.

The authors, from the University of Newcastle (Australia) based in Singapore, have been teaching an undergraduate course in EIA for the last 10 years [5]. It is the only course at the undergraduate level that offers EIA in Singapore. In this paper, we will present 2 case studies on the limitations of using limited biodiversity studies to make decisions on clearing forested land for housing development. The case studies are situated in the Dover and Clementi forests. Mitigating measures are proposed such that either the forests are preserved or a restricted development is allowed, while preserving part of the forest.

\section{References}

[1] Land Transport Authority, Singapore (2021, 6 June). Environmental Impact Assessment, Phase 2 Report. Available: https://www.lta.gov.sg/content/ltagov/en/newsroom/2019/9/2/environmental-impact-assessment-phase-2-report.html

[2] T.T. Guttensohn, K.P. Leong, in Pang Sua Woodland: Sanctuary Unveiled Along the Rail Corridor. 2021. Cicada Tree EcoPlace, Nature Society Singapore. ISBN: 978-981-14-9944-9.

[3] J. Chun and L.H. Lye, in Environmental Law in Singapore. 2019. Singapore Academy of Law. ISBN: 978-981-14-2035-1

[4] R. Hicks, T. Ha, S. Sambhi, R. Teng and G. Parker. (2021, 4 July). A City In Nature or A City Without Nature: The Uncertain Faith of Singapore's Last Forests. Available: https://eco-business.shorthandstories.com/a-city-in-nature-or-a-city-withoutnature-the-uncertain-fate-of-singapores-last-forests/

[5] University of Newcastle (Australia) (2021, 7 July). Environmental Impact Assessment Course. Available: https://www.newcastle.edu.au/singapore/future-students/short-courses/envohs-short-courses/envs3610-environmentalimpact-assessment 